\title{
Лингвистические особенности выражения эмоций «радость/печаль» в русском и английском языках
}

\section{Linguistic Features of Expression "Joy/Sadness" in the Russian and English Languages}

Татьяна Александровна Сухомлина

(Самара, Россия)

\section{Абстракт:}

Статья посвящена описанию «радости/печали» как основных эмоций в когнитивной лингвистике на примере русского и английского языков. Автор утверждает, что изучение эмоций чрезвычайно важно для понимания широкого круга проблем, связанных с деятельностью человека и его личным опытом. Несмотря на то, что изучению эмоций посвящены многочисленные научные работы (Ю. Д. Апресян, А. Вежбицкая, Г. В. Колшанский, Н. А. Лукьянова, Е. Ф. Петрищева), эмотивность не готова предложить своего полного описания. Известно, что эмоции представлены на всех уровнях языковой коммуникации. Они предполагают желание человека установить и поддержать контакт с другими людьми. Автор утверждает, что стереотипы употребления выражений «радость/печаль» основаны на конкретной этнической общности, поэтому основные эмоциональные реакции рассматриваются носителями языка по-разному. Автор приходит к выводу, что различия выражения «радость/печаль» в русском и английском языках зависят от культурных факторов, порождающих специфический опыт переживания эмоций.

\section{Ключевые слова:}

эмоции; эмоциональный мир; радость/печаль; душевное состояние; речь; языковые средства; интерпретация; культурная обусловленность 


\section{Abstract:}

The article is devoted to the description of "joy/sadness" as the major emotions in the cognitive linguistics on the example of Russian and English languages. The author tells that understanding of these emotions is extremely important for learning different problems which are related to the human activity. In spite the fact that numerous scientific works are devoted to the study of emotions (Yu. D. Apresyan, A. Vezhbitskaya, G. V. Kolshansky, N. A. Lukyanova, E. F. Petrishcheva), emotivity is not ready to offer its full description. It is known that emotive components are presented at all levels of language communication. They suggest a person's desire to establish and maintain a contact with other people. The author states that stereotypes of using expressions "joy/sadness" are based on the specific ethnic community, so the basic emotional reactions are considered by native speakers differently. The author concludes that the difference of expression "joy/sadness" in Russian and English languages depends on the cultural factors which generate specific experience of emotions.

\section{Key words:}

emotions; emotional world; joy/sadness; state of mind; speech; language means; interpretation; ethnic community; cultural stereotypes

\section{Введение}

Человек как языковая личность отражает мир пристрастно, отбирая только то, что ему необходимо в данный момент, или то, что по каким-либо причинам представляется ценным. Этот процесс отражения регулируют, в частности, эмоции, выступая в роли посредника между окружающим миром и его представлением в языке.

Известно, что эмоции являются одной из наиболее сложно организованных систем психики человека, поэтому их исследованию и изображению в языке посвящены многочисленные работы ученых: Ю. Д. Апресян ${ }^{1}$, А. Вежбицкой ${ }^{2}$, Г. В. Колшанского ${ }^{3}$, Н. А. Лукьяновой ${ }^{4}$, Е. Ф. Петрищевой ${ }^{5}$. Изучение эмоций

1 APRESIAN, Ju. D.: Obraz čeloveka po dannym jazyka. Izbrannyje Trudy: T. V. Moskva: Nauka, 2000.

2 VEŽBICKAJA, A. Fazyk. Kul'tura. Poznanija. Moskva: Vysšaja škola, 2009.

3 KOLŠANSKIJ, G. V.: Ob’jektivnaja kartina mira v poznanii i jazyke. Moskva: Nauka, 2009.

4 LUK'JANOVA, N. A.: Ėkspressivnost' kak semantičeskaja kategorija. In: Jazykovyje kategorii v leksikologii i sintaksise. Novosibirsk: Nauka, 1991.

5 PETRIŠČEVA, Je. F.: Stilističeski okrašennaja leksika russkogo jazyka. Moskva: Nauka, 1984. 
представляет собой исключительную важность для понимания самого широкого круга проблем индивидуального опыта и человеческой деятельности в целом. Хотя фундаментальным исследованиям вербально-понятийного множества эмоций уделяется большое внимание в современной лингвистике, эмотивность как наука о языке еще не готова представить полное описание своей сущности. Актуальность последующего описания универсальных эмоций «радость/печаль» обусловлена необходимостью сопоставления способов их выражения и качественных различий в рамках когнитивной лингвистики.

\section{Методология}

Исследование эмотивных компонентов в языке началось В.И.Шаховским при изучении семантики слова ${ }^{6}$. По мнению Н. Д. Арутюновой, это связано с тем, что слово, являясь основной речевой единицей, в обыденном сознании представляет поле языка ${ }^{7}$. Проблематику коммуникативного аспекта значения слова довольно четко выделила Е.С.Кубрякова. По ее мнению, кардинальным вопросом коммуникативной лингвистики является вопрос о месте, которое категория значения занимает в процессе коммуникации. Этот вопрос сложен и делится на ряд составляющих: 1) в каком виде семантика включается в речевую деятельность; 2) каковы конкретные функции языкового значения в процессе речи; 3) какие этапы процесса речи связаны с созданием и использованием языкового значения; 4) с какими языковыми формами сопряжено его создание и использование ${ }^{8}$.

Выяснение коммуникативного аспекта значения слова предполагает его анализ с двух позиций - со стороны говорящего и слушающего. Исследование со стороны говорящего построено от личностных смыслов к поискам средств их языкового выражения, а второй вариант исследования представляет собой поиск ключевых фраз в процессе восприятия речи и установления содержащихся в них значений. Это еще одна сторона анализа коммуникативного аспекта значения слова, который происходит на пути от слова к предложению (высказыванию). Очень важная роль в таком случае отводится эмотивному компоненту значения слова, который представляет собой результат отражения эмоций в слове в процессе их вербализации и семантизации. Эмотивный

6 ŠACHOVSKIJ, V. I.: Kategorizacija èmocij v leksiko-semantičeskoj sisteme jazyka. Dis. ... dokt. filol. nauk: 10.02.19. Moskva, 1988.

7 ARUTJUNOVA, N. D.: Jazyk i mir čeloveka. In: Jazyk. Semiotika. Kul'tura. Moskva: Jazyki russkoj kul'tury, 1998.

8 KUBRJAKOVA, Je. S.: Nominativnyj aspekt rečevoj dejatel’nosti. Moskva: LKI, 2010. 
компонент значения предполагает индивидуальное выражение эмоциональной оценки окружающей действительности, а возможность его реализации происходит в особой эмоциональной ситуации общения.

Утверждение о том, что любое высказывание эмоционально можно объяснить тем фактом, что каждое общение мотивированно интересом или стремлением воздействия на кого-либо, а также потребностью в получении информации. Формы общения зависят от контекста, в котором они употребляются, и это положение находит подтверждение в различных лингвистических исследованиях. Например, Н. М. Разинкина провела исследование и показала, что даже в английских научных текстах можно найти эмоциональные компоненты речи 9 . В нехудожественных текстах на русском языке эмоционально окрашенные единицы встречаются уже с первой половины 18 века ${ }^{10}$, и этот факт говорит о важности эмоций в процессе коммуникации, а также о том, что для эмоций почти нет запретных сфер человеческого общения. В следующем отрывке из газетной статьи автор не только совмещает семантику радости и уверенности говорящего в будущих событиях, но и использует логическую цепь размышлений (...you'll open...; ... you'll hear...; You'll not know...; you'll not know...), выстроенную им для убеждения собеседника.

'What do you mean?'

'It means that some night you'll happily open the door of your "smart" refrigerator, and you'll hear a pleasant, cheerful voice... You'll not know how your refrigerator knows this, and what is worse, you'll not know who else your refrigerator is telling about it "Hey, Bob! I hear your celery is limp!"11

Представленная речевая ситуация показывает радостное эмоциональное состояние героя, которое выражается следующим предложением: Some night you'll happily open the door of your «smart» refrigerator, and you'll hear a pleasant, cheerful voice. Объектом радости говорящего является «умный» холодильник, который может поговорить со своим хозяином, сообщить ему о том, что происходит у него внутри, какие продукты испортились. К тому же, эмоция радости дополняется уверенностью говорящего посредством использования простых предложений с семантикой размышления.

Наиболее ярко эмоции представлены в текстах художественной литературы. Они насыщают произведение и вызывают у читателя сопереживание к героям. Например ситуация гнева в следующем отрывке:

9 RAZINKINA, N. M.: Stilistika anglijskoj naučnoj reči. Moskva: Nauka, 1972.

10 SERDOBINCEV, N. Ja.: Sootnošenije razgovornoj $i$ knižnoj reči, prijemy vvedenija èlementov razgovornoj reči $v$ nechudožestvennyje teksty proizvedenij pervoj poloviny XVIII veka. Perm': Izdatel'stvo Permskogo gosudarstvennogo universiteta, 2003, s. 61.

11 Herald International Tribune. December 3-4/12-13, 2014. 
Josephine: Why did you call me, mother? I don't see why I can't go to the movies with Lilian.

Mrs. Perry: Because you've got to study. You go somewhere every day, and your father wants it to stop.

Josephine: How crazy! How utterly insane! Father's got to be a maniac I think. Next thing he'll start tearing his hair and think he's Napoleon or something ${ }^{12}$.

Для описания психологического состояния главных героев, автор совмещает в отрывке эмотивную информацию, связанную с выражением чувств говорящих, экспрессивную информацию, отражающую силу воздействия на собеседника, и эстетическую, которая составляет художественно-выразительный аспект передачи мысли говорящим. Ведущую роль для выражения гнева здесь имеют предложения How crazy! How utterly insane! Для дополнения выражения эмоционального состояния героя автор использует в тексте метафору: Father's got to be a maniac I think... he'll start tearing his hair and think he's Napoleon or something.

Рассмотрим еще один фрагмент эмоциональной характеристики героя в художественном тексте:

Dr. Honey Taft: Your husband is not going to bother you anymore. You'll stay here until we find a place for you and your children to live, where you're well enough, you're going to have a job here at hospital.

Mrs. Owens: Do ... do you mean that?

Dr. Honey Taft: Absolutely. You'll have your own apartment with your children. You won't have to put up with the kind of horror you've been living through, and you'll have a decent, respectable job.

Mrs. Owens: I don't know how to thank you. You don't know what it has been like ${ }^{13}$. Директивные высказывания доктора Тафт, выраженные в максимально категоричной форме, отражают эмоцию радости и полную убежденность в правоте своих слов, что обеспечивает психологическое воздействие на собеседника: Your husband is not going to bother you anymore. You'll stay here until we find a place for you and your children to live, where you're well enough, you're going to have a job here at hospital. You'll have your own apartment with your children. You'll have a decent, respectable job. Дополнением к семантике радости является уверенность говорящего, которой способствует модальное слово Absolutely.

Эмотивные компоненты в языке являются средством описания психологического состояния, выраженного в речи говорящего. Они фиксируют значимую информацию в семантическое единство, функционирующее в различных

12 FITZGERALD, F.: The Ice Palace. Moskva: Progress Publishers, 196o, s. 74.

13 SHELDON, S.: Nothing lasts forever. Time Warner, 2010, s. 147. 
сюжетных ситуациях. В результате читатель получает представление об эмоциональном мире человека, которое формирует общее представление о его душевном состоянии.

\section{Результаты}

В течение долгого времени лингвистика занималась исследованием лексической и грамматической семантики в тексте, игнорируя тот факт, что эмоции и состояния регулируют процесс порождения речи и определяют интерпретацию окружающего мира. В зависимости от обстоятельств человек в языке фигурирует как субъект речи (говорящий), субъект сознания, восприятия, воли и эмоций. Поэтому одной из функций языка является экспрессивная функция. Предназначением этой функции является выражение субъективных аспектов восприятия человеком реального мира: эмоций, чувств, состояний, мнений, представлений о предметах.

Известно, что во все времена люди испытывали одни и те же чувства радости, печали, любви, грусти, поэтому психологи утверждают, что эмоции универсальны $^{14}$. Их состав отражает общечеловеческий опыт осмысления психической деятельности. Хотя учеными используются различные обозначения эмоций, словарь эмоций и состояний в разных языках не одинаков. Типологическая структура эмоциональной лексики в разных языках не совпадает и имеет национальную специфику, так как отражение эмоций в каждом языке самобытно. Культурная обусловленность выражения эмоции определяется тем, что она рождается в конкретной социально-исторической ситуации, в конкретной этнической общности.

Со времен Аристотеля немало было попыток создания универсальной классификации эмоций. Эти классификации резко отличались характером выдвигаемых оснований, числом выделяемых категорий и привлекаемых эмоций, а также самим подходом к различению эмоций и чувств. Например, представители древнегреческой философской школы стоицизма утверждали, что эмоции подразделяются на четыре вида: желание и страсть, печаль и страх ${ }^{15}$. Р. Декарт выделил больше - радость, любовь, печаль, ненависть, удивление, желание ${ }^{16}$. Основоположник классической психологии В. Вундт полагал, что нет достаточного количества слов, чтобы обозначить огромное количество

14 LEONT'JEV, A. I.: Potrebnosti, motivy i èmocii. In: Psichologija motivacii i èmocij. Moskva: ČeRo, 2006, ss. $57-79$.

15 IL'JIN, Je. P.: Ėmocii i čuvstva. Piter: Sankt-Peterburg, 2001, s. 130.

16 DEKART, R.: Strasti dusi. In: Izbrannyje proizvedenija. Moskva, 1950, s. 593-70o. 
эмоций ${ }^{17}$. Ученые Б. И. Додонов ${ }^{18}$, П. В. Симонов ${ }^{19}$ и У. Джеймс ${ }^{20}$ считают, что очень сложно классифицировать эмоции, так как трудно решить является ли выделенная эмоция уникальной или же схожей другими видами. Мы придерживаемся классификации эмоций на первичные (злость, стыд, вина, нежность) и вторичные потребности человека (ревность, страдание, отчаяние, позор), которую развивали О. Кондаш ${ }^{21}$, А. Е. Ольшанникова ${ }^{22}$. В основе этой классификации лежат основные потребности человека, к которым относятся эмоции «радость/печаль».

С нашей точки зрения базовая эмоциональная реакция «радость» носителями английского и русского языков мыслится как позитивное эмоциональное состояние, переживание которого важно и жизненно необходимо человеку. Радость позволяет восхищаться и наслаждаться миром. К.Изард называет радость простейшей эмоцией с точки зрения мимического выражения и возможности его расшифровки. Радуясь, человек улыбается или смеется, и эти проявления понятны. Они легко считываются. Ученый считает, что радость это результат исполнения желаний человека, его достижение цели. Наиболее ярко радость просматривается в художественных текстах. Например, одна из главных героинь романа М. А. Шолохова «Тихий Дон» мечтает быть рядом со своим возлюбленным. Она гордится своим женским счастьем, не позволяет вторгаться в личную жизнь и разрушать ее радость. Встречаясь с Григорием, Аксинья не прячется от людей. Она радуется жизни. Еще вчера для нее все было серо, а сегодня кажется, что мир радуется вместе с ней. Радость Аксиньи подчеркивается такими эмоциональными выражениями, как: «нести свою счастливую голову», целуя щетинистые щеки любимого», «мир казался ей ликующим и светлым» ${ }^{23}$. Они однозначны и придают речи выражение радости и неповторимый национальный колорит.

К. Изард приводит свидетельства о том, что чем труднее путь получения результата, тем ярче радость, сопровождающая исполнение желания ${ }^{24}$. Соглашаясь с В.А. Успенским, вспомним его описание радости: «Радость внутри человека. Это легкая светлая жидкость. Иногда она тихо разливается в человеке,

17 VUNDT, V.: Očerki psichologii. Moskva, 1912.

18 DODONOV, B. I.: V mire èmocij. Kijev: Politizdat, 1987.

19 SIMONOV, P. V.: Teorija otraženija i psichofiziologija èmocij. Moskva, 1970.

20 DŽEMS, U.: Psichologija. Moskva, 1991.

21 KONDAŠ, O.: Volnenije: strach pered ispytanijem. Kijev, 1981.

22 OL'ŠANNIKOVA, A.Je.: K psichologičeskoj diagnostike èmocional'nosti. In: Problemy obščej, vozrastnoj i pedagogičeskoj psichologii. Moskva, 1978, s. 93-105.

23 ŠOLOCHOV, M. A.: Tichij Don. Moskva: Èksmo, 2015, s. 220.

24 IZARD, K.: Teorija differencial'nych èmocij. In: Èmocii čeloveka. Moskva: MGU, 2009. 
а иногда бурлит, играет, искрится, переполняет человека, переплескивается через край. По-видимому, она легче воздуха: человек от радости испытывает легкость. Он идет не чуя земли под ногами, парит и, наконец, улетает на седьмое небо» ${ }^{25}$. Таким образом, с одной стороны, эмоция радости является для человека потребностью, то есть целью и, с другой стороны, может сопутствовать событию, которое представляет для человека определенную значимость.

Соглашаясь с выводами К.О.Погосовой ${ }^{26}$ и проведя свое исследование ряда существительных в толковых словарях русского и английского языков, номинирующих эмоцию «радость» (счастье, триумф, эйфория, блаженство, экстаз, фурор, нирвана, восторг, восторженность, экзальтация, нега, благодать, торжество, восхищение, наслаждение, удовольствие, удовлетворение, упоение, веселье, отрада, возбуждение, услада, жизнерадостность, беззаботность, умиление, утешение, злорадство // pleasure, ecstasy, rapture, delight, bliss, felicity, triumph, happiness, excitement, exaltation, exultation, elation, enchantment, joy, joviality, thrill, enthusiasm, sunshine, glee, satisfaction, nirvana, admiration, gaiety, hilarity, merriment, mirth, enjoyment, gladness, contentment, gratification, amusement, cheer, liveliness, light-heartedness, self-fulfillment, malice, delectation, jubilance) мы пришли к выводу, что наиболее широко радость представлена выражениями в английской речи (38 слов в словаре).

Например, в следующем отрывке герой не сразу находит нужное слово, чтобы выразить радость, которую он переживает в данный момент:

"It's-it's"-Colonel Bantry struggled to express himself,-“it's-incredible-fantastic!"27

"I'm glad there is someone in the world who is quite happy, muttered a disappointed man as he gazed at the wonderful statue." 28

Выражения «невероятно», «фантастично», «я очень рад» в обоих случаях примеров передают эмоциональное состояние героя, его радость и восхищение по отношению к теме разговора. К тому же, выражения «incredible», «fantastic», «I’m glad» имеют дополнительную семантику возбуждения и восторга.

Исследование показывает, что количественное превосходство слов радости в английском языке по сравнению с русским (27 слов в словаре) подтверждает наличие в английском языковом сознании универсальных представлений. Причиной этому является тот факт, что различные культуры предлагают

25 USPENSKIJ,V.A.: $O$ veščnych konnotacijach abstraktnych suščestvitel'nych. In: Semiotika i informatika: T. I. Moskva: VINITI, 2010, ss. 78-151.

26 GOSOVA, K. O.: Koncepty èmocij v anglijskoj i russkoj jazykovych kartinach mira. Avtoref. dis. ... kand. filol. nauk: 10.02.20. Vladikavkaz, 2007.

27 CHRISTIE, A.: Puzzles. Moskva: Vysšaja škola, 1983, s. 45

28 WILDE, O.: Happy Prince. Moskva: Martin, 2019, s. 27 
человеку разные возможности для переживания радости. Среди них можно назвать социальные и культурные условия, порождающие у человека усталость и скуку, условия вынуждающие людей бороться за выживание $\mathrm{e}^{29}$.

Для сравнения сопоставим эмоцию «радость» с отрицательным значением «печаль». Согласно К.Изард печаль имеет свои универсальные причины: 1) смерть близкого друга или члена семьи; 2) долгая разлука как физическое, так и психологическое состояние; 3) крушение надежд или разочарование; 4) неудача в достижении определенной цели ${ }^{30}$. Как правило, основной причиной печали является чувство утраты, которая может быть временной или постоянной, реальной или воображаемой. Руководствуясь общепризнанным мнением, мы относим «печаль» к числу отрицательных эмоций.

Исходя из выборки толковых словарей русского языка, печаль может быть представлена 28 выражениями (горе, несчастье, горесть, горечь, скорбь, прискорбность, кручина, отчаяние, мука, боль, невзгода, безутешность, сожаление, страдание, печаль, тоска, меланхолия, ностальгия, уныние, грусть, скука, хандра, разочарование, расстройство, подавленность, растерянность, прострация, апатия). В то время как в английском языке она составляет 34 выражения (anguish, grief, heartache, heartbreak, broken heart, woe, sorrow, pain, hurt, ache, pang, scar, affliction, agony, wound, sadness, suffering, despair, gloom, distress, desolation, bereavement, dole, yearning, mourning, depression, discontent, melancholy, nostalgia, ennui, boredom, lassitude, apathy, emptiness).

Печаль в русском языке довольно часто связана с пониманием внутренней информации в тексте. Она опирается на фоновые знания читателя и факты, представленные в произведении. Рассмотрим следующий отрывок:

«Через минуту явилось письмо. Так и есть: от матери, из Р-й губернии. Он даже побледнел, принимая его. Давно уже не получал он писем; но только теперь и еще что-то другое вдруг сжало ему сердце» ${ }^{31}$.

Вся информация о том, что герой давно не получал писем от матери, его печаль, сопряжена с волнением и предчувствием чего-то нехорошего, может быть даже беды, о чем свидетельствует выражение «что-то сжало ему сердце». Предчувствие Раскольникова не обмануло его в дальнейшем, а информация в данном письме предвосхитила последующие события в жизни главного героя.

29 DODONOV, B. I.: V mire èmocij. Moskva: Politizdat, 1999.

30 IZARD, K.: Teorija differencial'nych èmocij. In: Èmocii čeloveka. Moskva: MGU, 2009.

31 DOSTOJEVSKIJ, F. M.: Prestuplenije i nakazanije. Moskva: AST, 2015, s. 315 
В следующем примере также нет прямого указания на печаль, испытываемую героем. Интерпретация этого состояния опирается на знания читателем всего произведения:

- Графиня... - сказал Денисов с опущенными глазами и виноватым видом, хотел сказать что-то и запнулся. Наташа не могла спокойно видеть его таким жалким. Она начала громко всхлипывать ${ }^{32}$.

Представленные ранее выражения для обозначения печали придают тексту эмоциональную насыщенность. Это стартовый набор синонимичных обозначений эмоций для описания душевного состояния любого человека. Использование разных выражений зависит в первую очередь от культуры говорящего и от ситуации общения. Соглашаясь с выводами П. К. Анохина, можно утверждать, что на переживание человека и на его длительность в большей степени влияют социокультурные факторы. «Возможно, самым важным детерминантом горя является утрата роли. Роль отца, матери, ребенка, мужа и т.д., предписанная культурой, и потеря любимого человека часто означает утрату соответствующей роли» ${ }^{33}$. Добавим, что в русской культуре терпение и умение переносить страдания - это способ делать дело, способ ответа на внешние обстоятельства, способ существования в мире - основа личности человека. В этом своем качестве терпение и самоограничение являются не только показателем силы духа, но имеют более глобальное значение - принцип существования, поддержания гармонии и равновесия в мире.

Итак, «радость/печаль» и их языковые обозначения часто встречаются в русском и английском языках. Они включают в себя представление о характере эмоции в определенной лингвокультуре, о ее месте среди множества других эмоций, о причинах, вызывающих эти эмоции. Важно быть знакомым с типами выражения эмоций и уметь их интерпретировать в тексте.

\section{Заключение}

Являясь частью лингвокультуры народа, эмоции «радость/печаль» имеют особые черты для русского и английского языков. Несмотря на свою общеизвестность, они обладают различными формами выражения и воплощают в себе субъективный образ действительности. На протяжении нескольких веков эмоции в тексте представляют собой не только трансляцию между поколениями культурно значимых установок, но и, что более важно, служат формированию культурного самосознания носителей языка.

32 TOLSTOJ, L. N.: Vojna i mir. Moskva: AST, 2015, s. 620.

33 ANOCHIN, P. K.: Ėmocii. Psichologija èmocij: chrestomatija. Peterburg: Piter, 2004. 
Проведенное исследование показывает, что количественное превосходство выражения эмоций «радость» (38 слов) и «печаль» (34 слова) в английском языке отличается качеством, интенсивностью и глубиной этих эмоций. В русском языке эти эмоции предполагают меньшую дифференциацию и специализацию в выражении («радость» - 27 слов, «печаль» - 28 слов).

По количеству дифференциации можно утверждать, что эмоции в английском языке более детализированы и, как следствие, представлены различными оттенками и значениями. Это связано с определенными универсальными доступными человеку моделями, которые связаны с местными, специфическими реалиями, типичными для англичан. В повседневной жизни эмоции «радость/печаль» взаимно дополняют друг друга и расширяют объем эмоциональной сферы человека. Неповторимость каждого языка и его эмоциональной сферы очевидна при изучении эмоций в сопоставлении, что было проиллюстрировано на примере английского и русского языков.

\section{Литература:}

ANOCHIN, P. K.: Èmocii. Psichologija èmocij: chrestomatija. Peterburg: Piter, 2004. APRESIAN, Ju. D.: Obraz čeloveka po dannym jazyka. Izbrannyje Trudy: T. V. Moskva: Nauka, 2000.

ARUTJUNOVA, N. D.: Jazyk i mir čeloveka. In: Jazyk. Semiotika. Kul'tura. Moskva: Jazyki russkoj kul'tury, 1998.

DEKART, R.: Strasti dusi. In: Izbrannyje proizvedenija. Moskva, 1950.

DODONOV, B. I.: $V$ mire èmocij. Kijev: Politizdat, 1987.

DODONOV, B. I.: V mire èmocij. Moskva: Politizdat, 1999.

DOSTOJEVSKIJ, F. M.: Prestuplenije i nakazanije. Moskva: AST, 2015.

DŽEMS, U.: Psichologija. Moskva, 1991.

FITZGERALD, F.: The Ice Palace. Moskva: Progress Publishers, 1960.

Herald International Tribune. December 3-4/12-13, 2014.

CHRISTIE, A.: Puzzles. Moskva: Vysšaja škola, 1983.

IL'JIN, Je. P.: Ėmocii i čuvstva. Piter: Sankt-Peterburg, 2001.

IZARD, K.: Teorija differencial'nych èmocij. In: Èmocii čeloveka. Moskva: MGU, 2009. KOLŠANSKIJ, G. V.: Ob’jektivnaja kartina mira v poznanii i jazyke. Moskva: Nauka, 2009.

KONDAŠ, O.: Volnenije: strach pered ispytanijem. Kijev, 1981.

KUBRJAKOVA, Je. S.: Nominativnyj aspekt rečevoj dejatel'nosti. Moskva: LKI, 2010. 
LEONT'JEV, A. I.: Potrebnosti, motivy i èmocii. In: Psichologija motivacii i èmocij. Moskva: ČeRo, 2006.

LUK'JANOVA, N. A.: Èkspressivnost’ kak semantičeskaja kategorija. In: Jazykovyje kategorii v leksikologii i sintaksise. Novosibirsk: Nauka, 1991.

OL”ŠANNIKOVA, A. Je.: K psichologičeskoj diagnostike èmocional'nosti. In: Problemy obščej, vozrastnoj i pedagogičeskoj psichologii. Moskva, 1978.

PETRIŠČEVA, Je. F.: Stilističeski okrašennaja leksika russkogo jazyka. Moskva: Nauka, 1984 .

POGOSOVA, K. O.: Koncepty èmocij v anglijskoj i russkoj jazykovych kartinach mira. Avtoref. dis. ... kand. filol. nauk: 10.02.20. Vladikavkaz, 2007.

RAZINKINA, N. M.: Stilistika anglijskoj naučnoj reči. Moskva: Nauka, 1972.

SERDOBINCEV, N. Ja.: Sootnošenije razgovornoj i knižnoj reči, prijemy vvedenija èlementov razgovornoj reči $v$ nechudožestvennyje teksty proizvedenij pervoj poloviny XVIII veka. Perm': Izdatel'stvo Permskogo gosudarstvennogo universiteta, 2003.

SHELDON, S.: Nothing lasts forever. Time Warner, 2010.

SIMONOV, P. V.: Teorija otraženija i psichofiziologija èmocij. Moskva, 1970.

ŠACHOVSKIJ, V. I.: Kategorizacija èmocij v leksiko-semantičeskoj sisteme jazyka. Dis. ... dokt. filol. nauk: 10.02.19. Moskva, 1988.

ŠOLOCHOV, M. A.: Tichij Don. Moskva: Èksmo, 2015. 720 s.

TOLSTOJ, L. N.: Vojna i mir. Moskva: AST, 2015.

USPENSKIJ, V. A.: O veščnych konnotacijach abstraktnych suščestvitel’nych. In: Semiotika i informatika: T. I. Moskva: VINITI, 2010.

VEŽBICKAJA, A. Jazyk. Kul'tura. Poznanija. Moskva: Vysšaja škola, 2009.

VUNDT, V.: Očerki psichologii. Moskva, 1912.

WILDE, O.: Happy Prince. Moskva: Martin, 2019.

\section{About the author}

\section{Tatiana Alexandrovna Sukhomlina}

Samara State University of Social Sciences and Education, Department of Foreign Languages, Samara, Russia

tanya-sukhomlina@yandex.ru

https://orcid.org/0000-0001-7062-8766

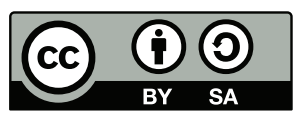

This work can be used in accordance with the Creative Commons BY-SA 4.0 International license terms and conditions (<https://creativecommons.org/licenses/by-sa/4.0/legalcode>). This does not apply to works or elements (such as images or photographs) that are used in the work under a contractual license or exception or limitation to relevant rights. 